\title{
ANTACID EVALUATION OF CARBONATED HYDROCALUMITES: A COMPARISON OF AGING METHODS
}

\author{
CARLOS F. LINARES ${ }^{*}, a$, JOEL MOSCOSSO ${ }^{a}$, VÍCTOR ALZURUTT ${ }^{a}$, FREDDY OCANTO $^{a}$, \\ PABLO BRETTO ${ }^{a}$, GEMA GONZÁLEZ ${ }^{b}$
}

\author{
${ }^{a}$ Unidad de Sintesis de Materiales y Metales de Transición. Facultad de Ciencias y Tecnología. Departamento de Química. \\ Universidad de Carabobo. Valencia. Edo. Carabobo. Venezuela. Apartado Postal 3336. Fax:+582418678243 \\ ${ }^{b}$ Laboratorio de Materiales, Centro Tecnológico, Instituto Venezolano de Investigaciones Científicas(IVIC), \\ Carretera Panamericana Km 11 Altos de Pipe, Los Teques, Venezuela.
}

\begin{abstract}
The synthesis of carbonated hydrocalumites could be troublesome because the carbonate anions can precipitate as calcium carbonate, therefore the aging times should be reduced. In this paper, carbonated hydrocalumites were synthesized using an unique gel divided in two portions: a part was aging to temperature room for $30 \mathrm{~min}$, and the other one, by microwave radiations for $2 \mathrm{~min}$. Samples were characterized by different techniques such as: Fourier-transformed infrared spectroscopy, X-ray diffraction, BET surface measurements, scanning electron microscopy (SEM) and energy dispersive X-ray spectroscopy (EDX). Then, they were tested as antacid using a synthetic gastric juice. Results showed that carbonated hydrocalumites aging by microwave radiations were more flawless than those obtained by the conventional method. Moreover, using microwave radiations, the aging times were notably reduced and the purity of carbonated hydrocalumites was improved. The antacid properties were similar for hydrocalumites synthesized by different ways. However, they showed they showed better antacid properties with higher antacid capacity than commercial antacid.
\end{abstract}

Keywords: carbonated hydrocalumite; microwave radiation; antacid; carbonate calcium; aging times

\section{INTRODUCTION}

Hydrocalumites are a close family of hydrotalcites-type (LDH) materials. They are classified as anionic clays. The general formula has been described as $\left.\left[\mathrm{Ca}_{2} \mathrm{M}^{3+}(\mathrm{OH})_{6}\right]\left(\mathrm{A}^{\mathrm{n}-}\right)_{1 / n} \cdot \mathrm{mH}_{2} \mathrm{O}\right]$, where $\mathrm{M}^{3+}$ is often a $\mathrm{Al}^{3+}$ cation. The hydrocalumite structure is constructed by the periodical stacking of positively charged $\mathrm{Ca}^{2+}$ octahedral layers related to brucite-like mineral and negatively charged interlayers consisting of diverse anions $\left(\mathrm{A}^{\mathrm{n}}\right)$ and water molecules. The $\mathrm{Ca}^{2+} / \mathrm{Al}^{3+}$ ratio is fixed in two. These structures are seven and sixfold coordinated. The seventh ligand of the $\mathrm{Ca}^{2+}$-polyhedron corresponds to water molecules from the interlayer ${ }^{1,2}$

Due to its basic properties, they have been used in several reactions such as: oil castor bean and rapeseed oil transesterifications $\mathrm{s}^{1,3}$, isomerization ${ }^{4}$ glycerol etherification ${ }^{5}$, aldolic condensation ${ }^{6}$, 2-cyclohexen-1-one catalytic epoxidation ${ }^{7}$, catalytic transfer hydrogenation of citral $^{8}$, biodiesel ${ }^{9}$ and recently as antacid ${ }^{10}$.

The synthesis of hydrocalumites is often carried out by the co-precipitation method using calcium and aluminum salts which are added to a basic solution containing sodium hydroxide and sodium nitrate or chloride salts. Reaction conditions for the precipitation are: temperatures between 60 and $80{ }^{\circ} \mathrm{C}$ under magnetic agitation for 12-48 $\mathrm{h}$. Other methods such as: sol-gel and homogeneous precipitation with urea have also been applied ${ }^{11}$.

However, new routes of hydrocalumites synthesis should be formulated when carbonate ions are hoped in the hydrocalumite's structure because the presence of this anion in the reactant gel is frequently precipitated as calcium carbonate. So, large aging times favor the formation of calcium carbonate.

The microwave radiation is known as a novel alternative when shor aging times are required for the synthesis of materials. In addition, this method allows obtaining more homogeneous materials, modifying some properties and consequently, energy saving.

The microwave radiation has been applied in the synthesis of chloride hydrocalumites to obtain higher crystalline samples using relatively short aging times compared to conventional aging times ${ }^{12}$. In this sense, Granados-Reyes et al. ${ }^{13}$, synthesized nitrated hydrocalumites by the microwave radiation method, and found really small crystals.

The aim of this paper was to synthesized carbonated hydrocalumites using two different aging ways: by microwave radiations and using an aging conventional method (room temperature, atmospheric pressure and stirring for $30 \mathrm{~min}$ ). Synthesized carbonated hydrocalumites were characterized by different techniques such as X-ray diffraction (XRD), Fourier transformed infrared spectroscopy (FT-IR), BET specific surface area measurements, scanning electron microscopy (SEM) and energy dispersive X-ray spectroscopy (EDX). Then, these synthesized carbonated hydrocalumites were tested as antacid materials in vitro using a synthetic gastric juice.
Antacids are substances able to increase the stomach's $\mathrm{pH}$ until an ideal $\mathrm{pH}$ when the organism cannot normally do it. Heartburn is caused under certain conditions such as stress, inadequate nutrition or several diseases ${ }^{14}$.

\section{EXPERIMENTAL}

\subsection{Synthesis of carbonated hydrocalumites $(\mathrm{HC})$}

The carbonated hydrocalumite gel was synthesized by the co-precipitation method previously reported by López-Salinas et al ${ }^{4}$. Two gels were prepared: in a general procedure, a calcium and aluminum solution was prepared dissolving $\mathrm{Al}\left(\mathrm{NO}_{3}\right)_{3} \cdot 9 \mathrm{H}_{2} \mathrm{O}(3.8235 \mathrm{~g})$ and $\mathrm{Ca}\left(\mathrm{NO}_{3}\right)_{2} \cdot 4 \mathrm{H}_{2} \mathrm{O}(3.3475 \mathrm{~g})$ in distilled water $(25 \mathrm{~mL})$. This solution was added dropwise to $50 \mathrm{~mL}$ of a solution containing $\mathrm{NaOH}(4.0745 \mathrm{~g})$ and $\mathrm{Na}_{2} \mathrm{CO}_{3}(0.2672 \mathrm{~g})$, this gel was aging under microwave radiation.

On the other hand, a similar gel as above mentioned, was prepared using $\mathrm{Na}_{2} \mathrm{CO}_{3}(1,0776 \mathrm{~g})$. This gel was aging at room temperature for 30 min under agitation.

After the gel preparations, the gel corresponding to the microwave radiation was placed in a Teflon recipient inside domestic microwave $(120 \mathrm{~V}$ and $60 \mathrm{~Hz}$ of power consumption) with operating power of $1250 \mathrm{~W}$ and a frequency of $2450 \mathrm{MHz}$ for $2.5 \mathrm{~min}$. The microwave power was controlled by adjustable independent channels. The synthesis was carried out using the first channel.

By using the conventional method, the gel was magnetically stirring at room temperature and atmospheric pressure for $30 \mathrm{~min}$.

After aging, a white precipitate was obtained. Solids were filtered from the mixture, washed with abundant distilled water and dried at $100{ }^{\circ} \mathrm{C}$ for $18 \mathrm{~h}$

To ascertain the effectiveness of the carbonated hydrocalumites as antacid, its behavior was compared with a commercial antacid containing hydrotalcite as active agent.

\subsection{Characterization of hydrocalumites}

Solids were characterized by different techniques such as: powder X-ray diffraction (XRD), BET specific surface area measurements, Fourier transformed infrared spectroscopy (FT-IR), scanning electron microscopy (SEM) and energy dispersive X-ray spectroscopy (EDX). XRD studies were conducted in a Phillips PW 3442 diffractometer with a CuK $\alpha$ radiation $(1,54060 \AA$ ) for crystalline phase detection between 5 and $85^{\circ}(2 \theta)$, and obtained patterns were compared with JCPDS data files. Physisorption measurements were performed with a Beckman Coulter SA 3100 instrument; BET specific surface areas were done using the $\mathrm{N}_{2}$ adsorption at $-196^{\circ} \mathrm{C}$. The presence of functional groups and evaluation of purity of solids were achieved by FT-IR; spectra were recorded 
in a Perkin-Elmer 283 spectrometer between 3900 and $400 \mathrm{~cm}^{-1}$. Samples were prepared mixing the solids with $\mathrm{KBr}$ to form a thin pastille. Scanning electron microscopy (SEM) was carried out on Hitachi FESEM-4500. Samples were previously covered with carbon for its observation. Energy dispersive X-ray spectroscopy (EDX) was carried out on EDAX, model 8400 to determine the composition of samples.

\subsection{Antacid capacity}

Antacid capacities of carbonated hydrocalumites were evaluated using the methodology previously reported by Rivera et al. ${ }^{15}$ and Linares et al..$^{10}$ Solids were tested in a synthetic gastric juice $(\mathrm{HCl}+$ pepsin, $\mathrm{pH} \square 1.5)$, contacting 30 to $150 \mathrm{mg}$ of the solids with an aliquot of $10 \mathrm{~mL}$ of a synthetic gastric juice. This dispersed solution was shaken during one hour at $37^{\circ} \mathrm{C}$ to simulate the rhythmical movements of the stomach. The solution was then filtered and an aliquot of $10 \mathrm{~mL}$ was evaluated using a calibrated $\mathrm{pH}$ meter.

2.

\subsection{Characterization of carbonated hydrocalumites}

Synthesized carbonated hydrocalumites by microwave radiation and a conventional method were characterized by FT-IR (Figure 1).

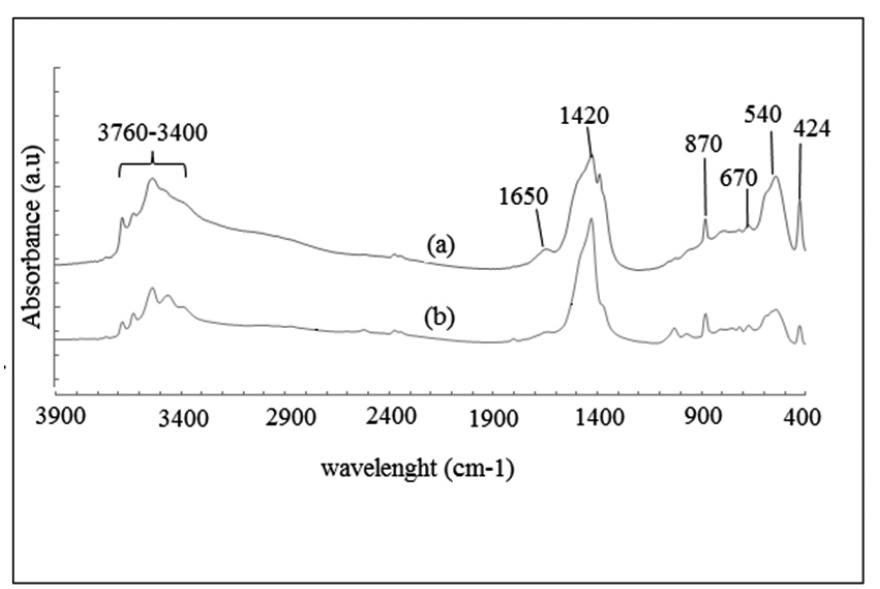

Figure 1. FT-IR of synthesized carbonated hydrocalumites by: a) microwave radiations and b) a conventional method.

Both samples showed similar spectra. A wide band between 3760 and $3400 \mathrm{~cm}^{-1}$ is associated to diverse functional groups. Two bands between 3500 and $3600 \mathrm{~cm}^{-1}$ could be attributed to $\mathrm{OH}^{-}$groups; while, the band at 3639 $\mathrm{cm}^{-1}$ corresponds to $\mathrm{O}-\mathrm{H}$ stretching vibrations in structural $\mathrm{Al}-\mathrm{OH}$ groups. The band at $3485 \mathrm{~cm}^{-1}$ could be assigned to $\mathrm{OH}$ groups of $\mathrm{Ca}(\mathrm{OH})_{2}$ present in hydrocalumites-type materials ${ }^{16,17}$. Also, $\mathrm{OH}^{-}$groups corresponding to water molecules placed in the hydrocalumite interlaminar region could be overlapped with the other two bands ${ }^{18}$.

On the other hand, bands at 1420 and $870 \mathrm{~cm}^{-1}$ correspond to O-CO vibrations of $\mathrm{CO}_{3}$ - ions in the interlayer region ${ }^{19}$. The band at $1420 \mathrm{~cm}^{-1}$ corresponding to the synthesized sample by microwave radiations seems wider than that of a synthesized sample by the conventional method which could be associated to smaller crystal size or a higher carbonate ions amount.

The small band at $870 \mathrm{~cm}^{-1}$ could be associated to the carbonation occurred during the manipulation of samples ${ }^{12}$. This carbonate species appear precipitated on the hydrocalumite surface, and are probably found as a calcium carbonate salts.

A band at $1650 \mathrm{~cm}^{-1}$ confirms the presence of physisorbed water.

Between 670 and $540 \mathrm{~cm}^{-1}$, Al-O vibrations of the hydrocalumite structure were observed ${ }^{20}$. Bands below to $424 \mathrm{~cm}^{-1}$ belong to Ca-O vibrations.

However, for a clear identification of the hydrocalumite phase, XRD patterns of both samples will be discussed (Figure 2).

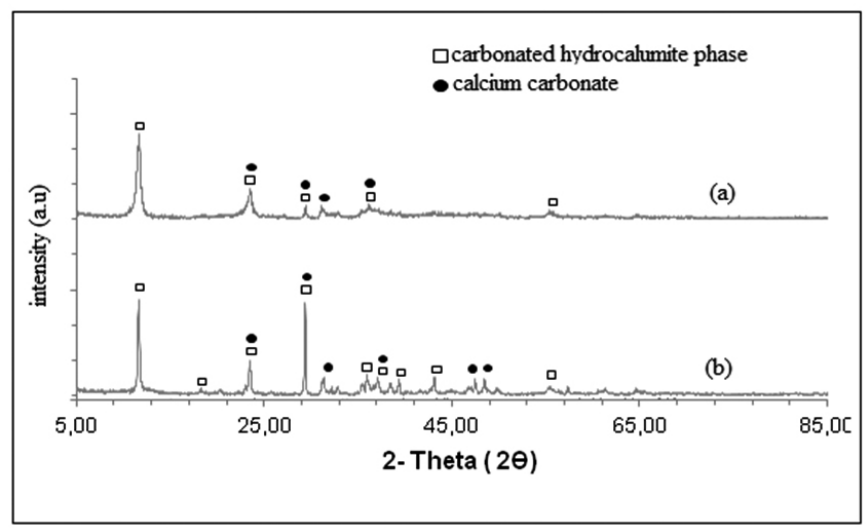

Figure 2. XRD patterns of synthesized carbonated hydrocalumites by: a) microwave radiations and $\mathrm{b}$ ) a conventional method

Characteristic intense reflections at: $10^{\circ}((001)$ and (003) planes), 23 $((006)$ and (009) planes) $(2 \theta)$, and also other less intense peaks between at $40^{\circ}(012)$ and $45^{\circ}(015)(2 \theta)$, belonging to carbonated hydrocalumites (JCPDS 035-0105) were found for both corresponding samples.

The hydrocalumite phase appears very crystalline for both synthesized samples, however a second phase of $\mathrm{CaCO}_{3}$ (JCPDS: 85-1108) was also found for both samples. This phase is characterized by an intense signal at around $30^{\circ}$ $(2 \theta)^{21}$, and it was more intense for synthesized samples by the conventional aging method. During the aging time increases the exposition of gels to the atmosphere $(30 \mathrm{~min})$ which could produce a higher formation of the calcium carbonate phase on the hydrocalumite surface.

BET specific surface area measurements of carbonated hydrocalumites were 18 and $25 \mathrm{~m}^{2} / \mathrm{g}$ for synthesized samples by conventional and microwave radiation methods respectively. Two factors could be responsible of the low specific surface area for the synthesized sample by the conventional method: a big crystal size and the presence of a high concentration of calcium carbonate on the hydrocalumite surface. The XRD pattern of synthesized sample by the conventional method shows a high concentration of calcium carbonate outside of the hydrocalumite surface.

In order to determine the size and the morphology of synthesized sample crystals, SEM was carried out to selected samples (Figure 3).

Figure 3(a) shows an image of a synthesized sample by the conventional method. Two different crystal's shapes were observed: large cubic crystals with an average size of $0.75 \mu \mathrm{m}$ together smaller crystals with hexagonal-type plate morphology with an average crystal size of $\leq 0.25 \mu \mathrm{m}$. Larger crystals would correspond to calcium carbonate salts and the small to the carbonated hydrocalumite.

The EDX analysis confirmed the presence of calcium carbonate and the hydrocalumite phase. In Figure 3(b) corresponding to a synthesized sample by the conventional method, two areas were analyzed: area 1 corresponding to carbonated hydrocalumite crystals due to $\mathrm{Ca}^{2+} / \mathrm{Al}^{3+}$ ratio close to 2, and an area 2 belonging to calcium carbonate crystals due to a low aluminum composition and high calcium content.

Carbonated hydrocalumite synthesized by microwave radiation showed the presence of hexagonal-type plate crystals corresponding to a homogeneous hydrocalumite phase with an average crystal size of $2.5 \mu \mathrm{m}$ (Figure 4(a)). The calcium carbonate phase was not observed which could be related to a low concentration of this salt. 


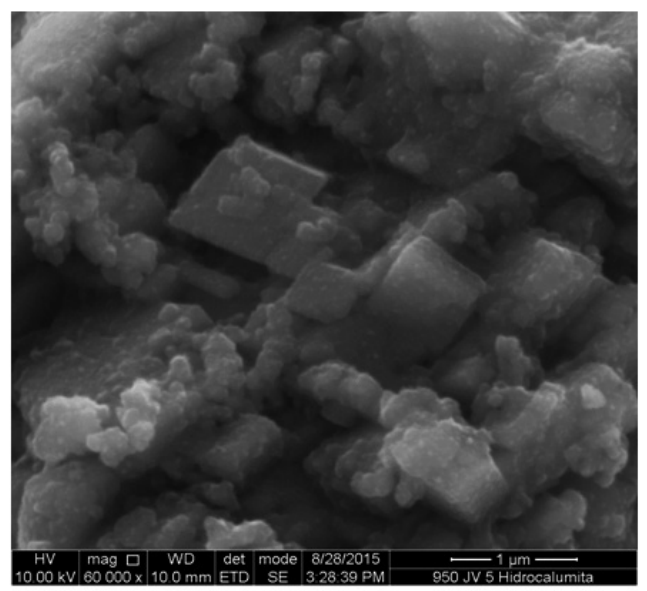

(a)

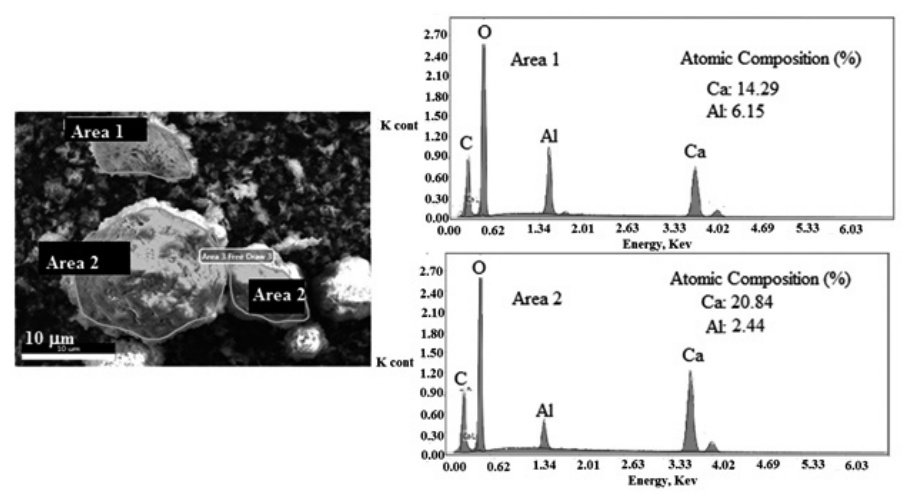

(b)

Figure 3. a) SEM image b) EDX analysis. Carbonated hydrocalumite sample synthesized by a conventional method.

Usually, it is reported that materials synthesized using microwave radiation, shown smaller crystals than those obtained by other methods. In our case, we do not observe significant differences.

On the other hand, the EDX analysis of a selected wide area showed a $\mathrm{Ca}^{2+} / \mathrm{Al}^{3+}$ ratio close to 2 which is in agreement with SEM image corresponding to carbonated hydrocalumite.

\subsection{Antacid characterization}

Figure 5 shows the neutralization capacity as a function of carbonated hydrocalumite and commercial antacid masses.

In general, the behavior of solids was similar, the $\mathrm{pH}$ increases as the quantity of the studied solid is increased.

The carbonated hydrocalumites showed a higher antacid capacity than the commercial antacid. A very small amount of synthesized carbonated samples ( $\sim 67 \mathrm{mg}$ ) were needed to neutralize the acidity to an ideal $\mathrm{pH}(\mathrm{pH} \sim 4)$ in comparison with the commercial antacid $(\sim 87 \mathrm{mg})$. High amounts of these samples cannot be used as antacid because the "rebound effect" could appear which is characterized by a return of the gastric acid and their symptom after the antacid drug effect wears off ${ }^{22}$

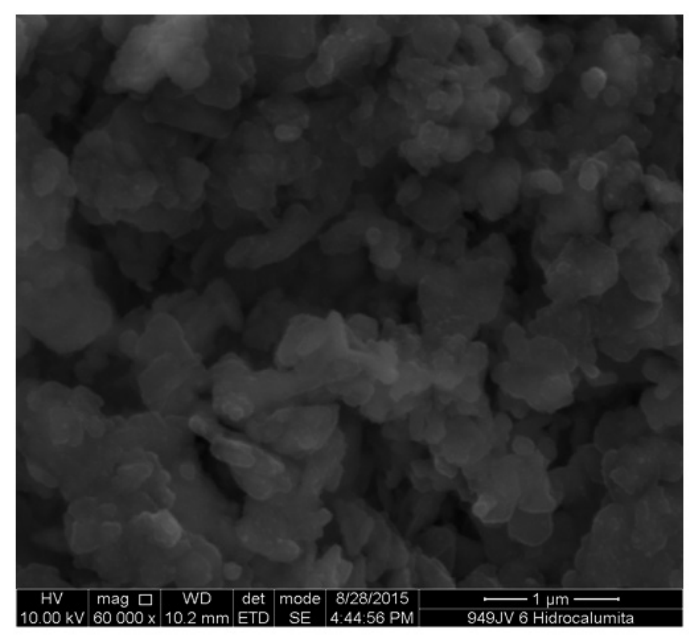

(a)
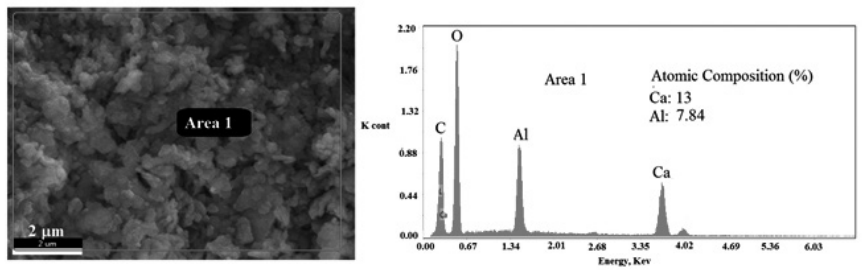

(b)

Figure 4. a) SEM image b) EDX analysis. Carbonated hydrocalumite sample synthesized by by microwave radiations.

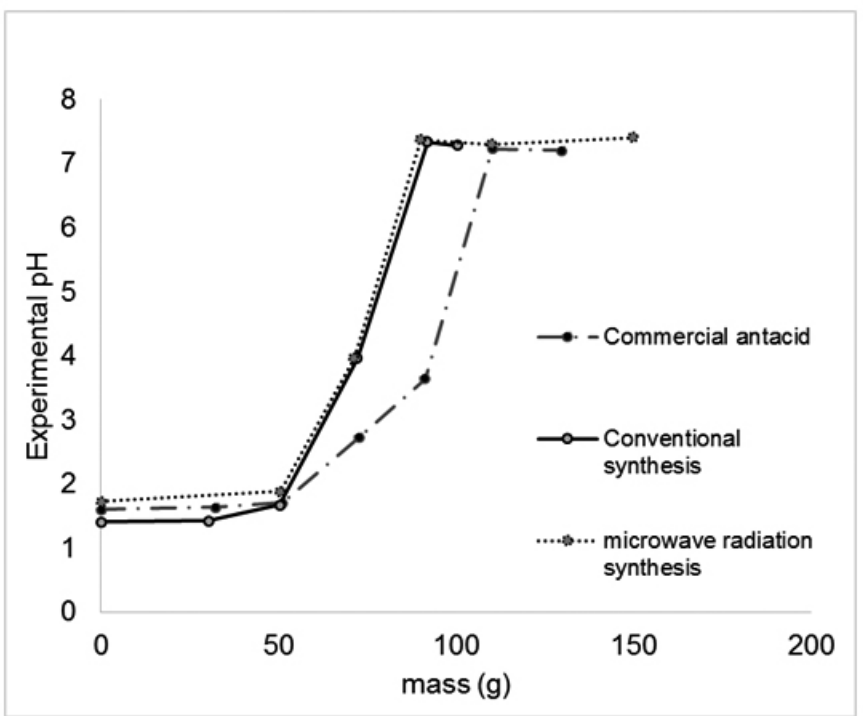

Figure 5. Neutralization capacity as a function of the amount of carbonated hydrocalumites and a commercial antacid tred (based on hydrotalcite). Experimental conditions: $37^{\circ} \mathrm{C}, 1 \mathrm{~h}$.

Carbonated hydrocalumites were synthesized with carbonate anions. Also, the hydrocalumite's structures are composed by aluminum cations; both species are known as effective antacids due to its buffer properties. The presence of carbonate anions increase the basic properties of hydrocalumites $(5.3 \mathrm{meq}$ $\mathrm{HCl} / \mathrm{g}$ solid) compared to a hydrocalumite synthesized with interlayer nitrate 
anions $(4.45 \mathrm{meq} \mathrm{HCl} / \mathrm{g} \text { solid })^{10}$.

However, differences between the neutralization capacity of carbonated hydrocalumite synthesized by microwave radiations and the conventional method were not observed. High carbonate concentration was obtained independently of the aging method used; the conventional method showed a high concentration of calcium carbonate on the hydrocalumite surface (determined by XRD), while by microwave radiation a high concentration of carbonate anion were observed in the hydrocalumite interlayer (determined by FT-IR). This could be an equilibrium which allowing to obtain similar results.

\section{CONCLUSIONS}

The synthesis and characterization of carbonated hydrocalumites by microwave radiation was possible. The aging time used for this synthesis was largely reduced $(2.5 \mathrm{~min})$ in comparison with a carbonated hydrocalumite synthesized by a conventional aging method $(30 \mathrm{~min})$. Moreover, homogeneous hydrocalumite crystals were obtained by a microwave radiation. Carbonated hydrocalumites showed a better performance as antacid than that of a commercial antacid. However, the antacid capacities of both synthesized carbonated hydrocalumites were similar.

\section{ACKNOWLEDGMENT}

Authors are grateful to Fonacit $\left(\mathrm{N}^{\circ} 201100379\right.$ and 2012001441) for financial support to this work.

\section{REFERENCES}

1. M. Sánchez-Cantú, L.M. Pérez-Díaz, N. Tepale-Ochoa, V.J. GonzálezCoronel, M.E. Ramos Cassellis, D. Machorro-Aguirre, J. Valente, Fuels 110, 23, (2013)

2. M. Sánchez-Cantú, S. Camargo-Martínez, L.M. Pérez-Díaz, M. Hernández-Torres, E. Rubio-Rosas, J. Valente, Appl. Clay Sci. 114, 509, (2015)

3. R. Segni, L. Vielle, F. Leroux, C. Taviot-Guèho, J. Phys. Chem. Solids, 67, 1037, (2006)
4. E. López-Salinas, M.E. Llanos-Serrano, M.A. Cotés-Jácome, I. SchifterSecora, J. Porous Mater. 2, 29, (1996)

5. E. Pérez-Barrado, M. C. Pujol, M. Aguiló, J. Llorca, Y. Cesteros, F. Díaz, J. Pallarès, L.F. Marsal, P. Salagre, Chem. Eng. J. 264, 547, (2015)

6. J. Cota, E. Ramírez, F. Medina, J.E. Sueiras, G. Layrac, D. Tichit, Appl. Clay Sci. 50, 498, (2010)

7. M. Sipiczki, A.A. Ádám, T. Anitics, Catal. Today, 241, 231, (2015)

8. M.A. Aramendía, B. Borau, C. Jiménez, J.M. Marinas, J. R. Ruiz, F.J Urbano, App. Catal., A: Gen. 206, 95, (2001)

9. J. Kocík, M. Hájek, I. Troppová, Fuel Process. Technol. 134, 297, (2015)

10. C.F. Linares, F. Ocanto, P. Bretto, M. Monsalve, Bull. Mater. Sci. 37, 341, (2014)

11. M. Mora, M.I. López, C. Jiménez-Sanchidrián, J.R. Ruiz, J. R. Catal. Lett. 136, 192, (2010)

12. E. Pérez-Barrado, M. C. Pujol, M. Aguiló, Y. Cesteros, F. Díaz, J. Pallarès, L.F. Marsal, P. Salagre, Appl. Clay Sci. 80-81, 313, (2013)

13. J. Granados-Reyes, P. Salagre, P. Y. Cesteros, Y, Microporous Mesoporous Mater. 199, 117, (2014)

14. M.H. Beers, R. Berkow, The Merk Manual of Diagnosis and Therapy, $10^{\text {th }}$ ed., Merk: Madrid, 1999.

15. A. Rivera, G. Rodríguez-Fuentes, E. Altshuler, Microporous Mesoporous Mater. 24, 51, (1998)

16. M. Mora, M. I. López, C. Jiménez-Sanchidrián, J. R. Ruiz, Solid State Sci. 13, 101, (2011)

17. S. Palmer, R. Frost, T. Nguyen, Coord. Chem. Rev. 253, 250, (2009)

18. M. Campos, J. Santamaría, J. Mérida, R. Moreno, M. Alburquerque, S. Bruque-Gámez, E. Rodríguez-Castellón, A. Jiménez-López, P. MairelesTorres, Energy Fuels 24, 979, (2009)

19. K-H. Kok, T-T Lim, Z. Dong, Water Res. 42, 1343, (2008)

20. M. Domínguez, M. Pérez-Bernal, R. Ruano-Casero, C. Barriga, V. Rives, R. Ferreira, L.D. Carlos; J. Rocha, Chem Mater. 23, 1993, (2011)

21. R. Frost, S. Palmer, F. Theiss, J. Raman Spectrosc. 42, 1163, (2011)

22. J. S.Fordtran, S. Morawski, C.T. Richardson, N. Engl. J. Med. 288, 923, (1973). 